\title{
A Democratic, Green Ocean Management Framework for Environmental, Social and Governance (ESG) Compliance
}

\author{
Evangelos Markopoulos ${ }^{1,2}$, Ines Selma Kirane ${ }^{1}$, Emma Luisa Gann ${ }^{1}$, \\ Hannu Vanharanta ${ }^{3,4}$ \\ ${ }^{1}$ HULT International Business School, Hult House East, 35 Commercial Rd, E1 1LD, \\ London, United Kingdom \\ ${ }^{2}$ Turku University of Applied Sciences. Faculty of Engineering and Business \\ Joukahaisenkatu 3, ICT-City, C-wing, FI-20520 Turku, Finland \\ ${ }^{3}$ University of Vaasa, School of Technology and Innovations, Wolffintie 34, 65200 \\ Vaasa, Finland \\ ${ }^{4}$ Poznań University of Technology, Plac Marii Skłodowskiej-Curie 5, 60-965 \\ Poznań, Poland \\ evangelos.markopoulos@faculty.hult.edu,kinesselma01@gmail.com,emma.gann@hot- \\ mail.de, hannu@vanharanta.fi
}

\begin{abstract}
In a dynamic and ever changing business landscape organizational sustainability is defined and redefined according to the socioeconomic challenges. This paper presents a practical framework that can significantly support organizational efforts on approaching, achieving, sustaining and improving its environmental, social and governance (ESG) strategies, objectives, and targets. The proposed framework, referred to as DESGGO (Democratic ESG Green Ocean) is based on the Company Democracy Model (CDM), covering the ESG governance elements/factors. Furthermore, the paper introduces a synergetic relationship between Corporate Social Responsibility (CSR) and ESG indicating the evolution of an organization to extend from applying outstanding governance practices, which lead to Blue Oceans, into outstanding social and environmental practices which lead to Green Oceans. The paper analyses the main ESG criteria per category and maps them on the DESGGO, six ESG and CSR progression levels moving the organization from Red to Green Oceans by adapting ESG practices.
\end{abstract}

Keywords: Innovation $\cdot$ Green Ocean $\cdot$ Red Ocean $\cdot$ Blue Ocean $\cdot$ Ethics $\cdot$ Sustainability $\cdot$ Governance $\cdot$ Democracy $\cdot \mathrm{CSR} \cdot$ Management

\section{Introduction}

Corporate competitiveness, values, and structures have always been related to the degree of sustainability that can be achieved. Well sustainably positioned organizations can absorb economic, market, financial and political turbulences, maintain operations, recover and return to their progressive and development course. However, under the new and current definition of sustainability, organizations are considered sustainable 
primarily through their environmental actions and ethical impact on society. Such goals shall be achieved with the same ethical dimension in corporate governance with respect to the people and the organizations itself. The three new pillars of organizational sustainability (environmental, social and governance) form the ESG factors, which contributes to better identify the organizational future financial performance in terms of return and risk. Research indicates that companies which adopted social or environmental standards achieved better operational performance and positive effect on the performance of their stock price [1]. ESG has turned out to be today a very important organizational valuation index that impacts significantly the investments in organizations [2]. The sustainable, responsible and impact (SRI) investment assets reached the 12 trillion dollars in 2018 from which the 11.6 trillion (8.1 trillion in 2016) is handled by asset managers that consider the ESG criteria [3].

One of the main strategies towards achieving high scores in the ESG criteria is the degree of sustainable innovation an organization applies on the development of its products, on the delivery of its services and on the governance of its people and operations. The impact of the ESG factors in the established organizations ignites a continuous quest beyond Blue Oceans. To achieve and maintain sustainability, it is required to think and act beyond the opportunities of the Blue Oceans. Organizations targeting high ESG scores aim to the Green Oceans, through sustainable innovations.

\section{Corporate Sustainability vs. Corporate Sustainability}

The recent waves of environmental activism have inflicted great attention and popularity on the term sustainability. In this context, sustainability is closely tied to environmental concerns. Regardless of those events, the Oxford dictionary describes the word essentially as "the ability to be maintained at a certain rate or level" [4], which allows for a great range of different interpretations and applications, possibly unrelated to tightly environmental matters.

In a corporate context, sustainability used to be considered from the perspective of a firm's operations. Operational Sustainability is concerned with determining the ability of a business to maintain its current practices and establishing proficiency to do the same in the future [5]. Furthermore, it describes the activity of managing the triplebottom-line, a firm's financial, social and environmental obligations and risks. The underlying financial sustainability element captures essential importance, as a company's historical main purpose is shareholder value. Thus, corporate sustainability out of a firm's perspective used to revolve around balancing a number of factors in order to enable the firm to operate successfully and profitable in the future.

However, with the recent trends thriving towards green thinking amongst individuals and corporations, the term Corporate Sustainability has been coined to a different meaning. Environmental concern is not only expressed through a half-hearted CSR campaign to improve reputation, but companies emerge, stating their sole purpose in helping the environment and omitting partly shareholder value.

The new meaning of Corporate Sustainability describes "the discipline by which companies align decision-making about the allocation of capital, product development, brand and sourcing with the principles of sustainable development" [6]. Therefore, 
companies are no longer solely concerned about sustaining their operations management, but sustaining their operations via sustaining the environment.

This shift from operational sustainability towards an environmental sustainabilityfocus has been occurring at a fast pace, driven by changing customer values and expectations. Today, corporate sustainability measures and initiatives are not only a form of competitive advantage, but they are a necessity for viability and survival. Customers, regulators and investors scrutinize firms regarding their environmental impact. This has led to the emergence of semi-official, but trendy, metrics, such as the ESG Index.

\section{ESG Index structure, dilemmas, and contradictions}

ESG comprises Environmental, Social and Governance dimensions in indexes and ratings. It specifically consists of a range of objectives on Best Practices for companies aiming to gain social consciousness \& ethics in operations, positive environmental impact, and meaningful economic profitability at scale. The investors/board members/ employee relationships, as well as company/stakeholders/market relationships, are evaluated and standardized against a best practice. The dimension of Governance refers to the way the power is exercised over the corporate entities. It focuses on the organization's direction and performance, strategy formulation, policy-making and accountability of the board. It is, by extent, framing the emergence, organization and dynamics within the board, as well as board-company and board-shareholders. Indeed, under the ESG standard "a new corporate governance approach" emerges [7]. Each dimension is composed of sub-categories where an in-depth evaluation is being undertaken by rating agencies.

The Environmental dimension has a nature-friendly meaning but can be understood also as business environment from a natural resource standpoint, comprising climate change, nuclear energy, and sustainability. The Social dimension focuses on diversity, equality, human rights, consumer protection, and animal welfare. For instance, ESG rating-organizations have a concern in animal testing for cosmetics \& medical products, where alternatives like cell-culture could be used instead. The Governance dimension covers management structure, employee relations, executive compensation, ethics, and employee compensation.

This paper addresses the very crucial issue related to the lack of consensus on the ESG rating methodology. Indeed, even if broad criteria have been expressed, the method of assessing the quality and the completeness of each dimension for a specific company varies from one rating agency to another. MSCI, Sustainalytics, Moody's, and S\&P Global are some examples of organizations that rate ESG differently. Therefore, any organization can come up with various ratings, depending on the criticality of each topic covered, and the overall methodology employed, creating serious contradictions on the methodology, the rating and the overall initiative [8]. Nauman affirms in the Financial Times that "this lack of standardization can be confusing for companies, whose ESG scores often do not match up across agencies." Other professionals believe that there will never be a unique ESG rating [9]. This paper attempts to tackle this issue by proposing a comprehensive rating methodology, as well as operations models and guidelines for companies to score high on the ESG, regardless of who is rating. 


\section{$4 \quad$ An ESG - CRS synergy towards Green Oceans}

Corporate strategies have been increasingly impacted by concerns on Sustainability, materialized by the ESG index. Sustainability is nowadays measured, indexed and benchmarked on various corporate strategies, ultimately aiming to homogenize the value creations standards toward shared-value innovation and long-term profitability.

Since the 1970s, Corporate Social Responsibility (CSR) is a prevalent concept in corporate strategy and development which started as an irrelevant or doubtful idea and got transformed into an indispensable organizational element widely recognized and accepted by business managers and stakeholders [10]. Over time regulators gave CSR a more institutional status linking it with organizational compliance on legal and ethical practices, something similar to what ESG does today. However, the meaning of CSR changed over the time by integrating characteristics towards representing a number of stakeholder rights, responsibilities, obligations, and various forms of philanthropic and charity activities [11]. Now the objective of CSR is to build business sustainable growth in a responsible manner [12]. Despite the growth of CSR, the concept did not seem strong enough to cope with the current global concerns. ESG took over and according to research CSR turned out to be mainly the Governance dimension of ESG [13]. Taking the evolution of the CSR and its integration with the ESG, a strategic synergy can be observed that can drive organizations from Blue Oceans obtained with ethical governance through the Company Democracy Model (CDM), into Green Oceans (Fig. 1)

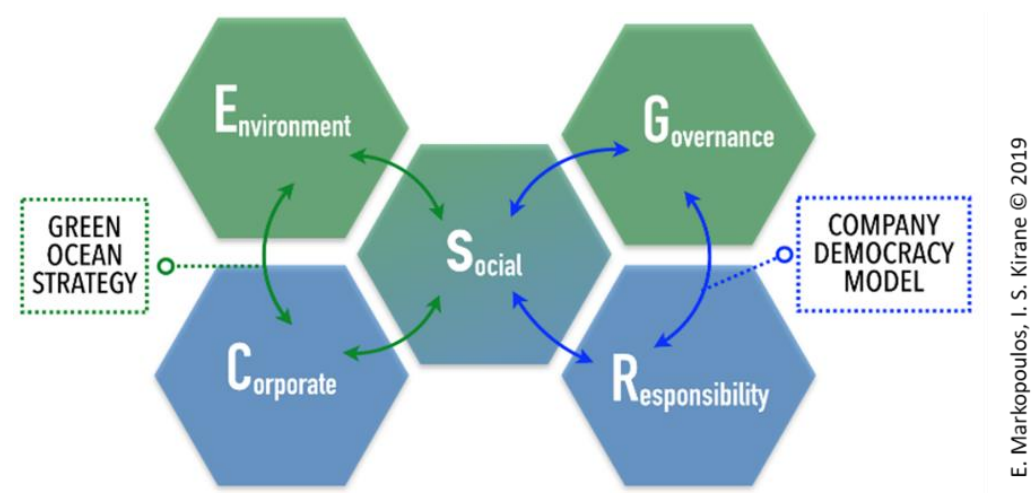

Fig. 1. ESG-CSR synergetic relationship

In this synergy the dimension of 'Corporate' refers to any practice of strategy, management, leadership and operations in an organization. It also comprises the value and cultural dimensions. 'Responsibility' relates to the relationships the company established internally and externally, respectively being managers-employees, managersboard, board-shareholders, and corporates-customers. 'Governance' comprises all practices and processes relative to power exertion, decision-making, interest-conflicts, and ethical strategic management. 'Environment' can be understood as the entire surrounding the business operates, referred as the business environment, or under the ESG meaning, the ensemble of Ecological, Economic, and Earth-friendly perspectives. The 'Social' dimension is the center pivot key of this system where all dimensions of both ESG 
and CSR can operate. It is the common ground on which companies can build addedvalue and meaning for long-term profitability and acknowledgment among peers and markets. The Social dimension refers to the employee-managers relationship, the company's legal compliance to social plans and governmental objectives, but mostly to the recognition of the societal-knowledge treasure, which can be democratically benchmarked for corporate innovation.

Value synergies are represented by the circular loops, corresponding to the principle that the whole is greater than the sum of the parts, adjusted to the value creation from ESG-CSR perspective. Value Synergies are profitability, benefits, and output amplification via the intricate relationships of long-term value creation components. This CSR-ESG synergy emphasizes the Green Ocean Strategy achieve by the integration of the Corporate, Environment, and Social dimensions, supported by the Company Democracy Model (CDM) [14], which creates organizations sustainability by integrating the Social, Governance, and Responsibility dimensions under a democratic perspective.

Several tools are available today for the integration and implementation of the Green Ocean Strategy such as the 3S Wide Innovation Matrix and the Turquoise Canal Strategy Conversion Methods [15], but also for the implementation Company Democracy Model such as the Evolute technology and Fuzzy system applications. The Company Democracy Model synchronizes in a collective way responsible governance (Fig. 2) for knowledge elicitation and transformation into corporate human intellectual capital (Fig. 3) [16]. These are examples of an array of models and protocols proposed for an ESGCSR Synergistic Innovation.

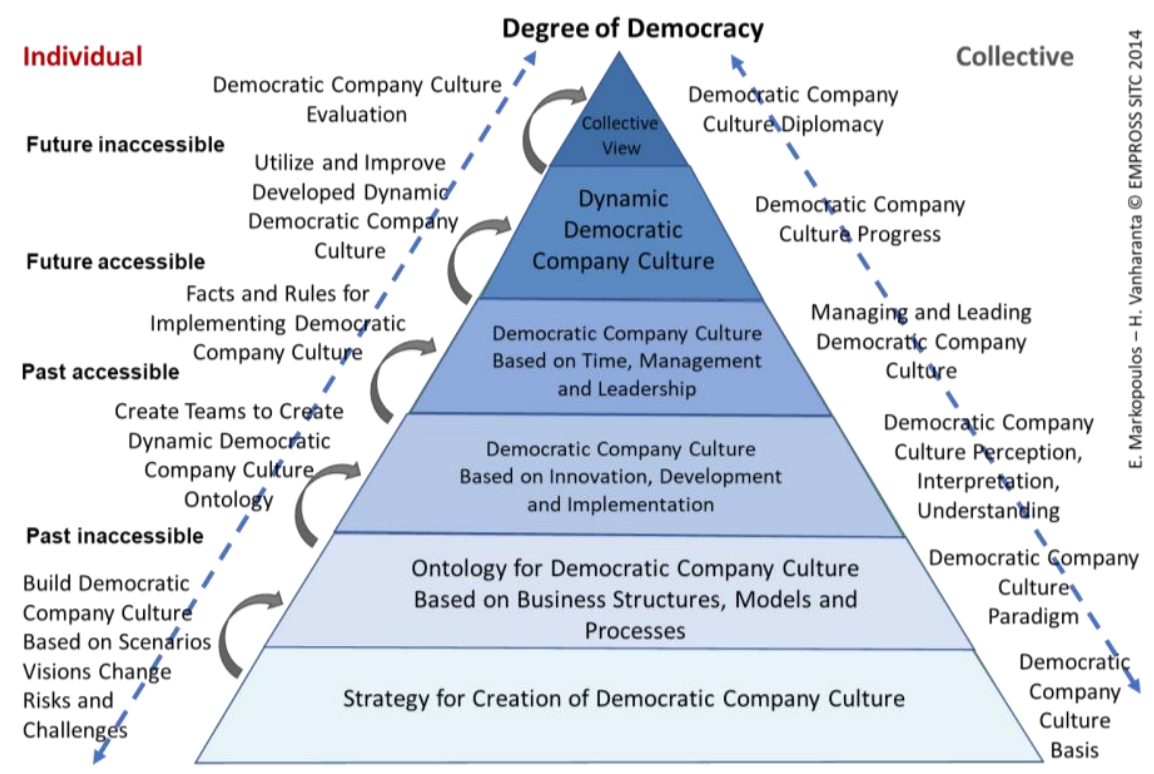

Fig. 2. Co-evolution of the individual and collective dimensions on the developing of a dynamic democratic environment 


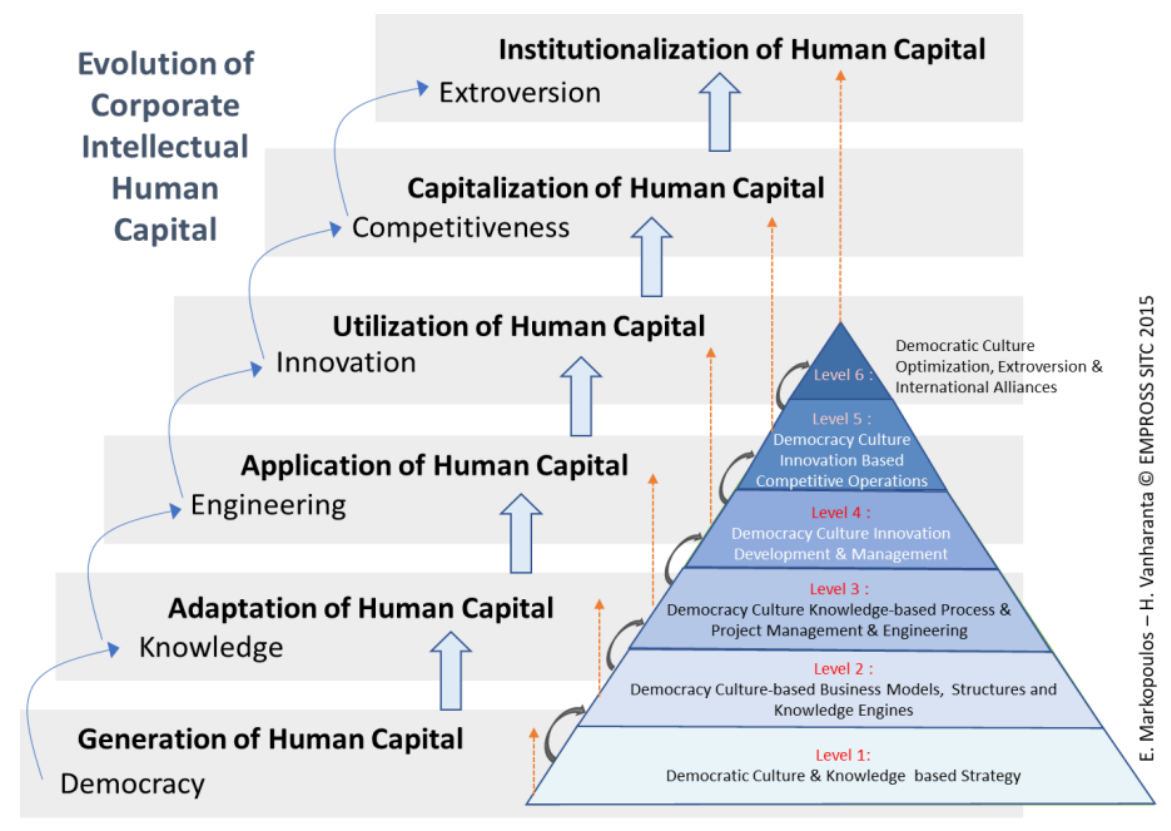

Fig. 3. Knowledge elicitations process incorporate democratic environments and its transformation into human capital.

\section{$5 \quad$ ESG-CSR Score through Green Ocean Strategy and Company Democracy Model}

The Green Ocean Strategy (GOS) and the Company Democracy Models are cornerstones of modern corporate Strategies as they provide Value Amplification via multiple layers of Synergies such as the ESG-CSR and among themselves with the CDM-GOS meta-synergy. Markopoulos and Kirane, et. al. [15] conceptualized the knowledge evolution for Green Oceans via the Company Democracy Model, providing companies with a framework of internal organizational management guidance for external strategic green alignment (Fig. 4). From the intellectual capital, green fuel production, that can be collected in a democratic culture for social and shared value innovation (level 1), this synergy establishes incremental steps to access Green Oceans (level 6).

The CDM driven Green Ocean Strategy fulfills all the ESG-CSR dimensions and contributes significantly to the company's ESG scorecard. The Environmental dimension is achieved with the green innovations derived from the GOS model which can be highly profitable. The Sustainability dimension can be approached by the GOS model either from the meaning of sustainability for the environment or from the sustainability for the company. Approaching sustainability from the environmental point of view can be considered as GOS innovation. On the other hand, organizational sustainability is achieved from the democratic element of the GOS that derives from the CDM and assures the continuous development of human intellectual capital for organizational innovation and competence. Lastly, the Governance dimension is achieved through the 
transparency, ethical and democratic organizational culture and governance offered by the democratic base of the CDM in the GOS.

Organizations that can deeply analyze the philosophy of the GOS and execute its operations can achieve significant ESG actions, results and ratings.

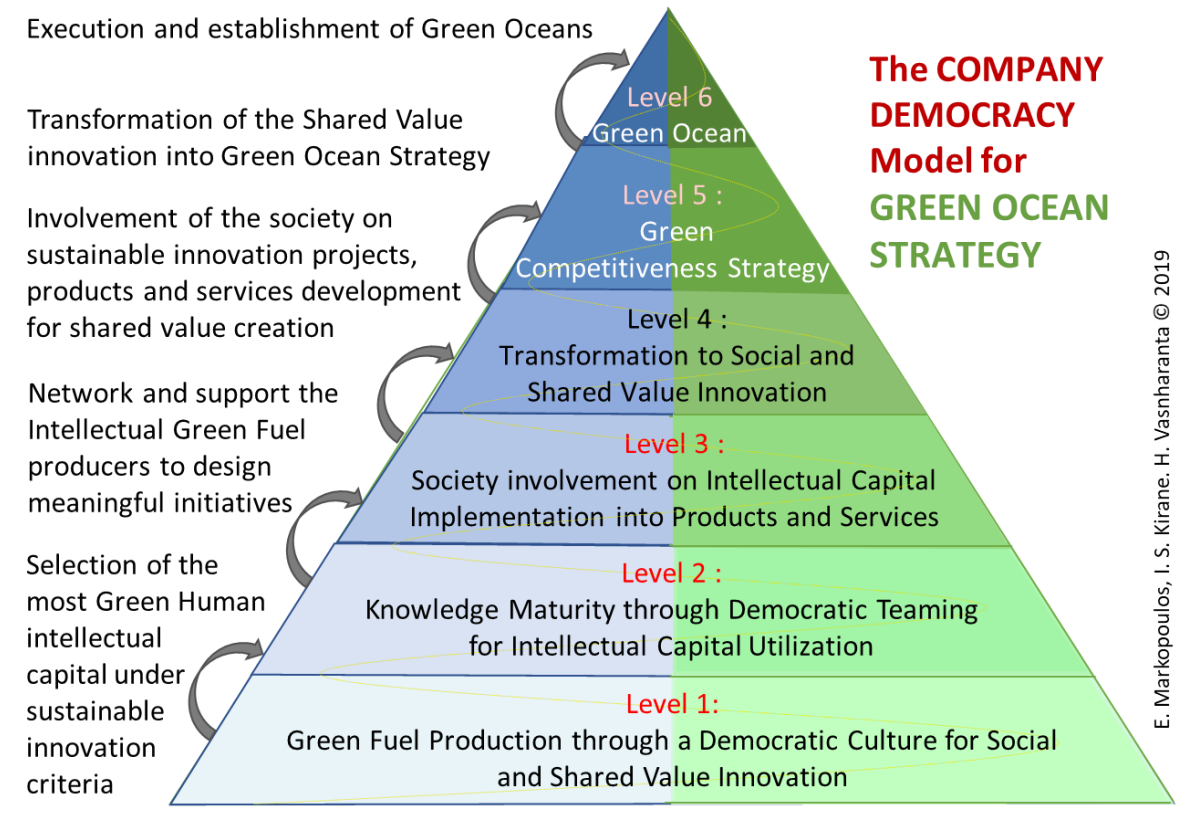

Fig. 4. Knowledge Evolution for Green Oceans via the Company Democracy Model.

\section{Diagnostic tool for ESG/CSR strategic mapping}

The Diagnostic Strategic Mapping from CDM to CSR and from GOS to ESG presents a way for companies to assess, along with their activities, the progression towards the ESG indexes. This mapping separates the Company Democracy Model (blue segment) and the Green Ocean Strategy (green segment), incremented by their respective $6+1$ levels (Fig. 5). Level 0 named 'Heroic Teams and Ad Hoc Processes', indicates that in every organization there is the will but not necessarily organized actions. The levels 1-6 of the Company Democracy Model are referred on the classic pyramid representation [14]. The levels 1-6 of the Green Ocean Strategy [15] originate the mapping: from a Conceptually Aware yet practically inactive organization (level 1), to the Implementation of Sustainable Culture Value and Strategies (level 2), for the establishment of business models and structures (level 3), that can lead to New Green Products/Services development (level 4), for Co-opetitive in Innovative Value Chain (level 5) needed to reach Sustainable, Meaningful and Impactful Profitably (Level 6), the ultimate stage where the highest score that can be attained. 
The term co-opetition, at level 5 , is the antagonistic philosophy of competition, promoting co-operation and collaboration for Sustainable Value Innovation and Amplification, the core of the Green Ocean Strategy.

This mapping covers an array of topics, from the most Governance-focused on the far left to the most Environment-focused on the far right. There is a common ground to the Company Democracy Model and the Green Ocean Strategy in their synergetic value, the Social factor. Social challenges are both central in the CSR/ESG relationship and in CDM/GOS dynamics. Therefore, this category stands on both segments, from the most corporate-focused on the far left to the most community-based on the far right.

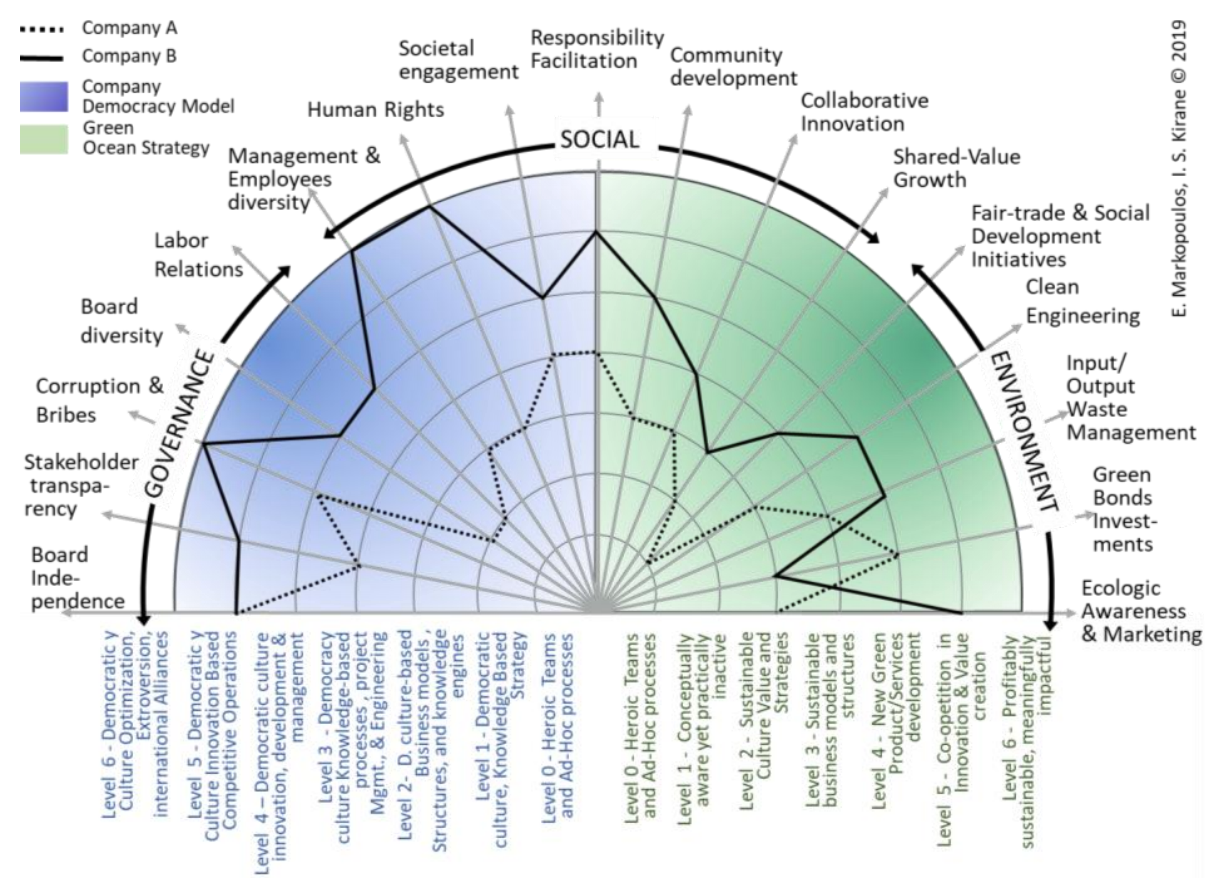

Fig. 5. Diagnostic Strategic Mapping: CDM to CSR and GOS to ESG

\section{Linear corporate restructuring in CSR \& ESG}

Most of the hierarchic multinational traditional companies are already progressing on the CSR by improving their Corporate Governance practices. The Linear CSR Restructuring for ESG high scoring proposes (Fig. 6) is a roadmap for companies aiming to score high on their ESG index, by tacking first their CSR challenges. Points of the ESG index are being progressively checked along with the roadmap as it follows.

In this linear approach, 'Responsibility' in governance covers the Corporate-Political Contributions, Executive Compensation, and Board Independence criteria of the Governance in ESG. By democratizing corporate procedures and processes via the various Company Democracy model versions, a company can both check the Governance and Social dimensions of the ESG Score. The Corporate-Political Contributions, Board 
Diversity, and Anti-corruption policies are being solved for the Governance dimension; while the Workplace Safety, Labour Relations, Diversity \& Bias, and Human Rights are being addressed on the Social dimension. The CSR monitoring \& conversion strategies correspond to the Turquoise Canal, an array of conversion strategies by allowing companies to successfully and effectively transition to the Green Ocean Strategy. This includes various models and planning \& feedback methodologies such as the $3 \mathrm{~S}$ Wide Innovation Matrix, or the ESG/CSR Strategic Mapping. Lastly, the integration of the Green Ocean Strategy is necessary for companies to score high on the ESG, as the philosophy itself allows for company to progress on socio-environmental matters: Green Building \& Smart Growth, Clean Technology, Decarbonization, Input Preservation, Clean Engineering for the Environmental dimension; and Community development, Collaborative/open innovation, and Workplace benefits on the Social dimension.

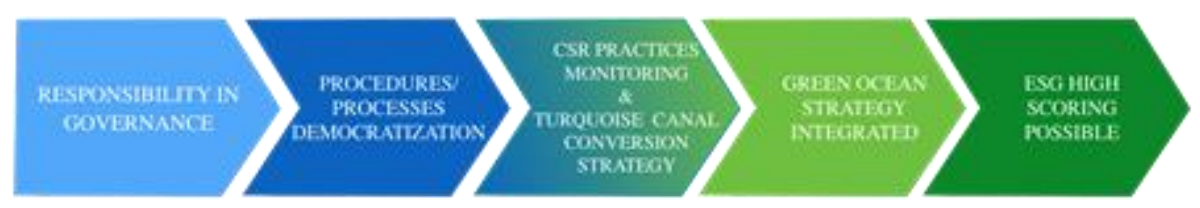

Fig. 6. The linear corporate transformation from CSR and ESG scoring

\section{The Democratic ESG Green Ocean Model}

The symbiosis on the ESG and the CSR practices under the Green Ocean Strategy for Environmental and Sustainable innovation and the Company Democracy Model for ethical and transparent Governance create the Democratic ESG Green Ocean Model (DeESGGOM). The model is visualized with a double pyramid with the internal, blue pyramid, to be the Company Democracy Model, representing the corporate Governance, and the external green pyramid to be the Sustainable and Environmental dimensions achieved from the integrations of the ESG and SCR practices (Fig. 7).

The Green pyramid (Environmental and Sustainability) follows the staged (leveled) concepts of the Company Democracy model and presents 6 levels of incremental development and organizational maturity towards reaching the optimal stage where high ESG scores and ratings can be achieved.

The first level of the model is related to the organizational culture where it identifies the degree of the ESG conceptual awareness and the distance from being practically active. The second level designs and executes an organizational sustainability culture by emphasizing on the added value for the organization from the people within (employees) or outside of it (clients, society). This is the stage where teams are being developed to ignite organizational culture and engage the society. The third level is the actual execution of this new ESG oriented organizational culture by adjusting the organizational business models and structures to reflect the ESG strategic goals. It is the level that the Governance dimension drives this level strongly. The fourth level is the outcome of the strategy execution where the new ESG oriented products and services are being developed. This level acts as the strategy proof of concept. The fifth level drives the co-opetition spirit needed for the organizations not to stay only on the new 
ESG driven products and services but also to invest and advance them into ESG driven innovation and gain the competitive advantage that can return profitability and sustainability. Lastly, the sixth level measures the sustainable and meaningful impact of the organization on the society and the profitability gained in financial and reputational terms. It must be noted that the Democratic ESG Green Ocean Model is an organizational management model and therefore profitability is related to the organizational sustainability needed to achieve and maintain the environmental sustainability.

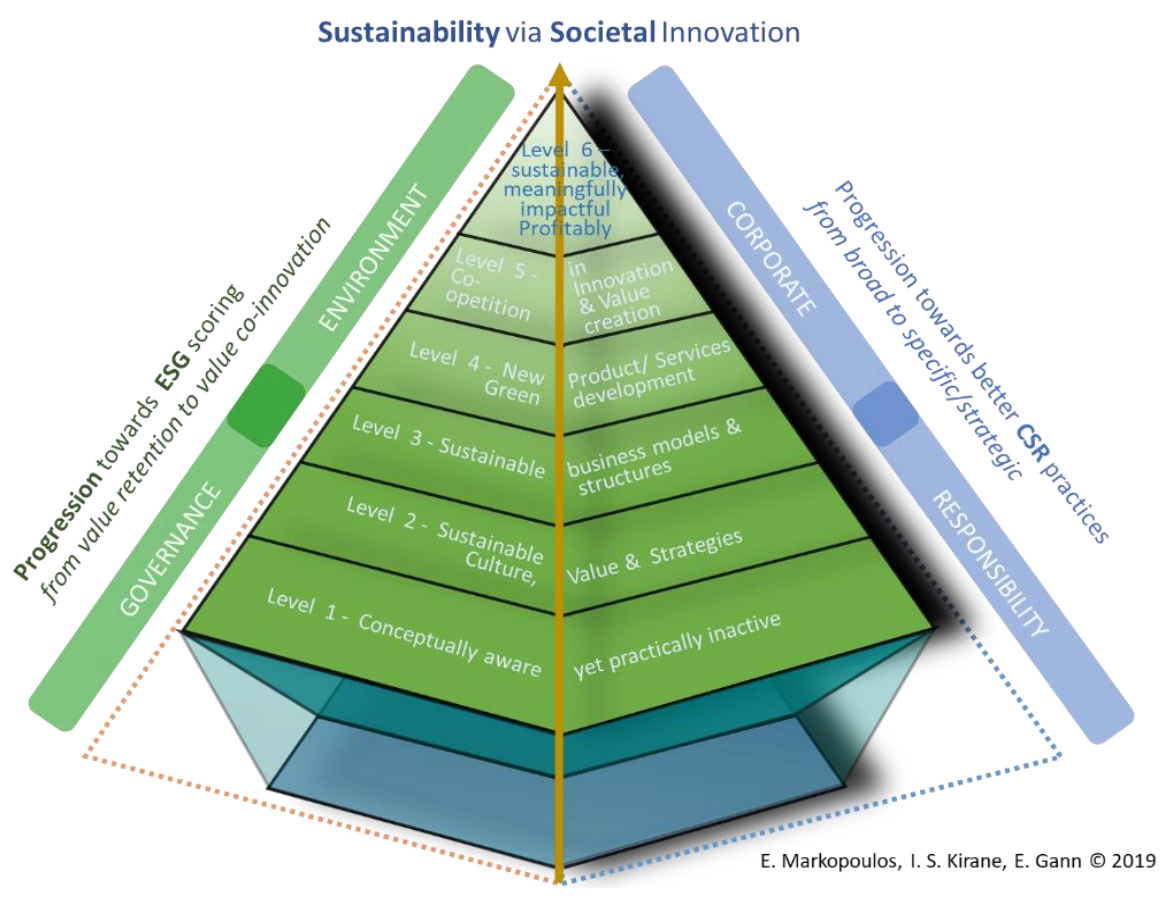

Fig. 7. The Democratic ESG Green Ocean Strategy Model structure.

\section{Applying the DeESGGO Model.}

The Democratic ESG Green Ocean Model can be applied from any type of organization regardless of its size and activity. ESG shall not be a rating privilege for large-scale organizations. Every company, small or large, can and should be thinking and acting under the ESG practices. However, the type of each organization impacts the time DeESGCO gets adopted and executed. There are various transformational archetypes categorized in the traditional companies, the multinational firms and the startups (Fig. 8). Traditional organizations or family businesses characterized by bureaucratic practices in their attempt to avoid mistakes and control their risk. Thus, they do not adopt modern management models and practices unless they are either forced by their clients, the government or impactful shareholders. In such organizations, the adaptation of DeESGCO can come at later stages of the Company Democracy model, usually at level 
4 where the organization is at the innovation stage meaning that the product development has successfully passed the market acceptance stage (CDM level 3).

On the other hand, multinational organizations do not wait long to adopt modern practices. It is their continuous search for new organizational and reputational gains that drives management and the shareholders to be more adaptive to the industry trends and demands. Such organizations, in order to reduce the risk, but not be late market entrants, can adopt the DeESGCO at the second level of the Company Democracy Model, once they secured that there is enough knowledge in their organizations (CDM level 1) structured in proper teams to utilize it (CDM level 2).

\begin{tabular}{|cc|c|}
\hline $\begin{array}{c}\text { Traditional Bureaucratic } \\
\text { Company }\end{array}$ & TRANSFORMATION ARCHETYPES \\
\hline Multinational Firm & Tech Start-Up \\
\hline
\end{tabular}

Fig. 8. The Democratic ESG Green Ocean Strategy Model structure.

Lastly, there is the start-up type of organization, and especially the tech-driven ones which are fully aligned with the global trends as organizational culture and founder's culture as well. Driven by the millennials, the tech startups are fully aware of the ESG elements, they understand them, accept them, and seek ways to integrate them in their businesses and delivering products and services highly related to the consumer concerns. These organizations do not lose any time to adopt DeESGCO as they don't have much to lose anyway. Therefore, DeESGCO is part of the first Company Democracy Model level and grows in parallel with the business operations since day one.

\section{Conclusions}

The ESG index is a modern trend in international business, impacting investments, profitability, reputation, marketing, client engagement and almost all the elements needed for an organization to sustain itself in a profitable way in a very competitive market. However, the very broad definition of the ESG concept does not allow the creation of a consensus between the rating organizations and the ones who invest in adapting such best practices. The distance that exists today in standardizing the ESG concept in rating and implementation creates opportunities for the researchers but significant challenges for the organizations. This paper attempted to approach the ESG challenges with the introduction of the Democratic ESG Green Ocean (DeESGCO) Model. The 
Democratic element contributes to achieving the Governance dimension while the Green Ocean Strategy contributes to achieving the Environmental and Sustainable dimension of the ESG. The paper introduced tools, practices and strategies for the application of the DeESGCO model such as the integration of the ESG and SCR, the Diagnostic Strategic Mapping, the Linear Transformation Process, the Transformational Archetypes and the DeESGCO model itself. However, true compliance with the ESG dimensions can only be achieved with the organizational culture and philosophy. It is easy to tick compliance boxes but not easy to convince that they have been really ticked. ESG is a valuable concept but it requires organizational leadership and self-awareness to bypass the political correctness and to practically comply with ESG for the shake of the organization, the society and the humanity.

\section{References}

[1] US News, https://money.usnews.com/investing/investing-101/articles/2018-06-28/how-esginvesting-increases-risk-adjusted-returns

[2] Wealthsimple. https://www.wealthsimple.com/en-us/learn/esg-investing\#pros_of_esg_investing

[3]. US/SIF (2018). Sustainable investing assets reach $\$ 12$ trillion as reported by the US SIF Foundation's biennial Report on US Sustainable, Responsible and Impact Investing Trends.

[4] Lexico. https://www.lexico.com/en/definition/sustainability

[5] Sony M. Implementing sustainable operational excellence in organizations: an integrative viewpoint, Production \& Manufacturing Research, 7:1, 67-87, (2019)

[6] GASCO. Defining and developing the corporate sustainability professional - the practitioners' view. May 2011, Version 1, (2011)

[7] KPMG https://home.kpmg/uk/en/home/insights/2019/11/investor-insights-esg-disclosures.html

[8] Financial Times. https://ftalphaville.ft.com/2018/12/06/1544076001000/Lies--damned-liesand-ESG-rating-methodologies/

[9] Financial Times, https://www.ft.com/content/59f60306-d671-11e9-8367-807ebd53ab77

[10] Hamidu A.A., Haron H., Amran A. Corporate Social Responsibility: A Review on Definitions, Core Characteristics, and Theoretical Perspectives. Mediterranean Journal of Social Sciences MCSER Publishing, Rome-Italy/pp 83-95. Vol 6 No 4 July 2015 (2015)

[11] Moon, J. Corporate Social Responsibility: An Overview, in C. Hartley, the International Directory of Corporate Philanthropy. Europa Publications, London. (2002)

[12] Moir, L. What do we mean by corporate social responsibility? Corporate Governance, Vol. 1 No. 2, pp. 16-22, (2001)

[13] Iamandi, I.-E., Constantin, L.-G., Munteanu, S.M., Cernat-Gruici, B. Mapping the ESG Behavior of European Companies. A Holistic Kohonen Approach. Sustainability, 11, 3276. (2019)

[14] Markopoulos E., Vanharanta H.: Democratic Culture Paradigm for Organizational Management and Leadership Strategies - The Company Democracy Model. Proceedings of the 5th International Conference on Applied Human Factors and Ergonomics AHFE 2014 (2014).

[15] Markopoulos E., Kirane I.S., Piper C., Vanharanta H. Green Ocean Strategy: Democratizing Business Knowledge for Sustainable Growth. In: Ahram T., Karwowski W., Pickl S., Taiar R. (eds) Human Systems Engineering and Design II. IHSED 2019. Advances in Intelligent Systems and Computing, vol 1026. Springer, Cham, (2020).

[16] Markopoulos E., Vanharanta. H.: The Company Democracy Model for the Development of Intellectual Human Capitalism for Shared Value, Procedia Manufacturing, vol 3, pp 603 $-610(2015)$ 